\title{
PKMS PEMBERDAYAAN IBU RUMAH TANGGA BERBASIS EKONOMI KREATIF MELALUI USAHA PEMBUATAN KUE TRADISIONAL DI BANJAR BLAHTANAH SUKAWATI
}

\author{
Putu Dian Pradnyanitasari ${ }^{1)}$; Putu Yudha Asteria Putri ${ }^{2)}$; Ida Ayu Agung Idawati ${ }^{3)}$ \\ Fakultas Ekonomi dan Bisnis Universitas Warmadewa \\ Email: dianpradnya@gmail.com
}

\begin{abstract}
Market snacks are foods that are usually bought from traditional markets. Until now the market snacks are still very popular for family snacks and served to guests. One type of market snacks that are well known from any times to the present is the sagon cake. In Bali the sagon cake which is commonly called "jaje sagon" is very popular, especially when it is approaching the feast day of "jage sagon" which is very popular in the market. This traditional cake made from coconut and sticky rice flour is the result of production from a home industry (IRT) business using simple equipment. The problems faced by partners include: 1) Do not have a bookkeeping or records related to income, expenses, production costs and profit and loss. 2) Do not have knowledge about management accounting practices related to the calculation of cost of production, cost of orders, capital budgeting and the performance of UMKM in conducting their business activities. 3) Do not understand corporate governance. 4) Don't have a marketing system like social media. 5) Unattractive product packaging and lack of product variation. The solutions offered for this problem are 1) Assisting in making simple financial books and reports. 2) Assist and provide management accounting training. 3) Provide training on the application of corporate governance, especially relating to the determination of production and marketing strategies. 4) Make social media to help in product marketing and provide assistance in its use. 5) Help make new packaging more attractive so that it can increase marketing and make alternative jaje sagon that is more varied from more contemporary flavors or forms.
\end{abstract}

Key Words : UMKM, Jaje Sagon

\begin{abstract}
ABSTRAK
Jajanan pasar merupakan makanan yang biasa dibeli dari pasar tradisional. Hingga saat ini jajanan pasar masih sangat digemari untuk camilan keluarga maupun disuguhkan untuk tamu. Salah satu jenis jajanan pasar yang cukup dikenal dari jaman dahulu hingga saat ini adalah kue sagon. Di Bali kue sagon yang biasa disebut "jaje sagon" sangat digemari, apalagi sewaktu menjelang hari raya "rerainan" jaje sagon sangat laku dipasaran. Kue tradisional yang berbahan dasar kelapa dan tepung ketan ini merupakan hasil produksi dari usaha industri rumah tangga (IRT) dengan menggunakan peralatan sederhana. Adapun permasalahan yang dihadapi oleh mitra meliputi: 1) Belum memiliki pembukuan atau catatan terkait pendapatan, pengeluaran, biaya produksi dan laba ruginya. 2) Belum memiliki pengetahuan tentang praktik akuntansi manajemen terkait dengan perhitungan biaya pokok produksi, harga pokok pesanan,
\end{abstract}


penganggaran modal serta kinerja UMKM dalam melakukan aktifitas bisnisnya. 3) Belum memahami tata kelola perusahaan. 4) Belum memiliki sistem pemasaran seperti sosial media. 5) Pengemasan produk yang kurang menarik serta kurang adanya variasi produk. Solusi yang ditawarkan untuk masalah ini adalah adalah 1) Melakukan pendampingan dan membantu dalam pembuatan pembukuan dan laporan keuangan sederhana. 2) Melakukan pendampingan dan memberikan pelatihan akuntansi manajemen. 3) Memberikan pelatihan mengenai penerapan tata kelola perusahaan terutama berkaitan dengan penentuan strategi produksi maupun pemasaran. 4) Membuatkan sosial media untuk membantu dalam pemasaran produk serta melakukan pendampingan dalam penggunaannya. 5) Membantu membuat kemasan baru yang lebih menarik sehingga dapat meningkatkan pemasaran serta membuat alternatif jaje sagon yang lebih bervariasi dari rasa ataupun bentuk yang lebih kekinian.

Kata Kunci : UMKM, Jaje Sagon

\section{PENDAHULUAN}

Banyak hal yang bisa kita banggakan dari Negara Indonesia ini. Selain alamnya yang indah dan budayanya yang beragam, Indonesia juga memiliki beragam makanan (kuliner) yang khas dan enak untuk dinikmati. Salah satu kekayaan kuliner Indonesia terlihat dari aneka jajanan pasar yang dimiliki. Jajanan pasar merupakan penganan yang biasa dibeli dari pasar tradisional (Bastian, 2016). Jenisnya beragam mulai dari yang rasanya manis hingga gurih. Hingga saat ini jajanan pasar masih sangat digemari untuk camilan keluarga maupun disuguhkan untuk tamu. Salah satu jenis jajanan pasar yang cukup dikenal dari jaman dahulu hingga saat ini adalah kue sagon (Franciscus, 2013).

Kue sagon bisa dijumpai di berbagai daerah di Nusantara dengan berbagai variasi bentuk. Di Bali kue sagon yang biasa disebut "jaje sagon" sangat digemari, apalagi sewaktu menjelang hari raya "rerainan" jaje sagon sangat laku dipasaran. Kue tradisional yang berbahan dasar kelapa dan tepung ketan ini merupakan hasil produksi dari usaha industri rumah tangga (IRT) dengan menggunakan peralatan sederhana. Kendati jaje sagon ini sangat digemari dan usahanya mempunyai prospek yang menjanjikan namun berdasarkan pengamatan dilapangan masyarakat di Bali sudah jarang yang mau menekuni usaha pembuatan kue tradisional ini.

Ibu Ni Wayan Sumerti merupakan salah satu pedagang yang menekuni usaha pembuatan jaje sagon. Lokasi usahanya berada di Banjar Blahtanah, Desa Singapadu Kaler, Kecamatan Sukawati - Gianyar yang sekaligus merupakan tempat tinggalnya. Usaha pembuatan jaje sagon ini sudah ditekuninya sejak 5 tahun yang lalu. Dalam 
menjalankan usahanya ibu yang berusia 35 tahun ini dibantu dengan mempekerjakan 7 orang tenaga kerja dengan upah yang dibayar harian yaitu sebesar Rp $12.000 / \mathrm{kg}$ tepung yang dihabiskan. Tenaga kerja yang membantu ibu Sumerti ini adalah 2 orang dewasa dan sisanya adalah anak-anak sekolahan yang bekerja sebelum atau sesudah pulang sekolah. Jaje sagon yang diproduksi oleh usaha rumahan ibu Sumerti biasanya dijual dengan harga Rp 1.000 yang berbungkus kecil dan Rp 10.000 yang berbungkus besar, dimana jaje sagon ini dijual ke pasar-pasar tradisional seperti pasar Sukawati, Gianyar, Blahbatuh dan salah satu pelanggan tetapnya yang berasal dari daerah Mengwi, Badung. Rata-rata penjualan yang diperoleh oleh Ibu Sumerti adalah sebesar Rp 800.000 - 1.000 .000 per harinya.

Bahan yang digunakan untuk membuat jaje sagon merupakan bahan yang mudah didapat yaitu tepung ketan, kelapa, gula pasir, garam dan vanili. Proses pembuatannyapun dapat dibilang mudah. Pertama-tama kelapa diparut, kemudian kelapa yang sudah diparut dicampur dengan bahan yang lainnya (tepung ketan, gula pasir, garam dan sedikit vanili). Bahan yang sudah dicampur menjadi satu dimasukkan ke dalam cetakan (wajan / teplon mini) yang sudah dipanaskan diatas api sedang kemudian dipanggang hingga matang sambil ditekan-tekan agar adonan menjadi pipih. Setelah matang kemudian dilipat dan digulung, terakhir dikemas dalam plastik ukuran kecil dan ukuran sedang besar. Peralatan yang digunakan oleh Ibu Sumerti masih sangat sederhana. Untuk memarut kelapa beliau masih menggunakan parutan biasa dengan kondisi tempat usaha yang kurang higienis selain itu untuk pengemasan hasil produksi, Ibu Sumerti masih menggunakan streples untuk menjepret plastiknya sehingga tidak jarang hasil kemasan robek dan menjadi tidak higienis. Semua proses pembuatan jaje sagon dikerjakan secara tradisonal dan manual dimana ibu Sumerti dan para pekerjanya berdiri selama 2,5 jam untuk memproduksi $1 \mathrm{~kg}$ bahan menjadi jaje sagon. 


\section{Gambar 1. Foto usaha Ibu Ni Wayan Sumerti}


Berkaitan dengan pengelolaan manajemen usaha pembuatan jaje sagon Ibu

Sumerti ini, maka dapat dideskripsikan kondisi dari usaha tersebut adalah sebagai berikut:

1. Manajemen pengelolaan usaha pembuatan jaje sagon Ibu Sumerti belum dilakukan secara professional karena dikelola secara kekeluargaan dan kurang pemahaman terhadap tata kelola perusahaan terutama berkaitan dengan strategi produksi dan pemasaran.

2. Ibu Sumerti tidak memiliki pembukuan/ catatan harian sama sekali terkait produksi, pendapatan, biaya, laba rugi, sehingga benar-benar tidak mengatahui dengan jelas kondisi dan posisi keuangan usahanya.

3. Ibu Sumerti belum memahami cara perhitungan biaya pokok produksi, harga pokok pesanan, penganggaran modal serta kinerja UMKM dalam melakukan aktifitas bisnisnya.

4. Usaha pembuatan jaje sagon Ibu Sumerti belum memiliki model pemasaran untuk mempromosikan hasil usahanya. Selama ini hanya mengandalkan pelangan tetapnya yakni pedagang di pasar Gianyar, Blahbatuh, Sukawati dan Mengwi.

5. Kemasan yang saat ini digunakan tidak memiliki daya tarik pasar, dimana jaje sagon hanya dibungkus plastik dan diberi streples saja. Pada plastik kemasan hanya diberikan logo usaha yang hanya menampilkan nama serta no telepon Ibu Sumerti saja. 


\section{METODE PELAKSANAAN}

\section{Solusi yang ditawarkan}

Pengabdian masyarakat yang dilakukan melalui pemberdayaan usaha pembuatan jaje sagon di Desa Batuan Kaler, Sukawati Gianyar dengan mitra pengusaha jaje sagon ini bertujuan untuk mengatasi permasalah yang dihadapi berkaitan dengan pengembangan usahanya. Adapun solusi yang dapat ditawarkan untuk mengatasi permasalahan mitra tersebut antara lain :

\section{Pembuatan Buku Laporan Keuangan Sederhana}

Pelaksanaan program ini dilakukan melalui pendekatan individual. Pendekatan individual ini diawali dengan menggali pemahaman mitra berkaitan dengan pembukuan. Setelah menggali pemahaman mitra mengenai pembukuan, kemudian dilanjutkan dengan memberikan materi dan pemahaman seperti apa bentuk dari buku keuangan sederhana serta apa saja isi dari buku keuangan sederhana. Kemudian, mitra diajak mencari tahu hal apa saja yang dibutuhkan jika ingin mengetahui berapa laba bersih yang dihasilkan dan berapa besar riilnya biaya yang dihabiskan serta membuat buku laporan keuangan sederhana. Setelah memberikan pemahaman, mitra kemudian diberikan sebuah buku kosong untuk diajak menyusun buku laporan keuangan sederhana.

Pendekatan ini menekankan para mitra untuk dapat membuat sebuah buku laporan keuangam sederhana. Mitra di dampingi oleh tim pengusul (ketua pengusul) untuk menyusun buku laporan keuangan sederhana. Mitra akan dibimbing dan didampingin untuk mencatat setiap hal yang berkaitan dengan pengeluaran biaya dan pemasukan dalam proses produksi dan pemasaran jaje sagon termasuk besarnya upah yang harus dibayarkan kepada tenaga kerjanya. Mitra diharapkan nantinya dapat membuat laporan keuangan sederhana, dapat mengetahui berapa besarnya biaya yang dihabiskan dalam proses pembuatan jaje sagon, bisa menentukan harga jual dan besarnya upah yang harus dibayarkan kepada tenaga kerjanya. Dengan pemahaman yang diberikan diharapkan nantinya kelangsungan usaha mitra dapat berjalan lancar dan berkembang. 


\section{Pelatihan Akuntansi Manajemen}

Selain mengetahui tentang buku laporan keuangan sederhana yang merupakan salah satu bagian dari akuntansi keuangan, mitra juga akan diberikan pemahaman tentang akuntansi manajemen, dimana akuntansi manajemen akan memberikan dasar pembuatan keputusan bisnis sehingga mitra bisa lebih siap untuk mengelola dan melakukan fungsi pengontrolan dalam menjalankan aktifitas bisnisnya.

Mitra pada nantinya diharapkan dapat mengetahui rincian biaya produksi, harga pokok, biaya overhead yang dapat dibayarkan untuk menunjang kegiatan operasional dalam aktifitas bisnisnya. Sehingga dengan adanya pemahaman tentang akuntansi manajemen mitra dapat merencanakan, mengevaluasi, dan mengendalikan kegiatan operasionalnya, serta untuk mengukur akuntabilitas penggunaan sumber daya yang digunakan.

\section{Pelatihan Penerapan Tata Kelola Perusahaan}

Mitra belum memahami tata kelola perusahaan terutama dalam hal menentukan strategi produksi dan pemasaran. Untuk mengatasi permasalahan tersebut, tim pengusul (anggota) akan membantu dalam memberikan penyuluhan tentang penerapan tata kelola perusahaan. Tim pengusul (anggota) akan memberikan penjelasan dan pendampingan dalam menentukan strategi produksi dan strategi pemasaran. Tim pengusul (anggota) juga akan memberikan penyuluhan bagaimana caranya agar tenaga kerja yang dimiliki oleh mitra mau bekerja maksimal lagi. Dengan adanya bantuan ini diharapkan nantinya mitra dapat menerapkan strategi yang tepat untuk usahanya sehingga usahanya dapat berkembang dan hasilnya lebih maksimal lagi.

\section{Pelatihan Dalam Membuat Sistem Pemasaran Produk}

Membantu mitra dalam memasarkan hasil produksinya, dimana selama ini mitra hanya mengandalkan pelanggan tetapnya yaitu pedagang di pasar Blahbatuh, Sukawati dan Gianyar saja dalam memasarkan hasil produksinya. Berdasarkan pendekatan individual yang dilakukan diketahui bahwa mitra merupakan orang yang tidak paham tentang teknologi informasi serta tidak tahu bagaimana cara memanfaatkan teknologi informasi tersebut. Oleh karena itu tim pengusul (anggota) akan memberikan pelatihan tentang strategi pemasaran, membantu dalam membuatkan akun sosial media seperti 
facebook dan instagram serta melakukan pendampingan dalam penggunaannya. Diharapkan nantinya dengan penggunaan sosial media tersebut mitra dapat memperluas pemasaran produknya. Selain itu (anggota) juga akan membantu membuat design terhadap kemasan produk jaje sagon ini, agar kemasan lebih menarik untuk dijual dan mencoba membuat variasi rasa serta bentuk jaje sagon yang kekinian sehingga dapat memingkatkan daya jual.

\section{HASIL DAN CAPAIAN}

Berikut ini capaian pelaksanaan kegiatan sesuai dengan yang diprioritaskan pada masing-masing mitra, yaitu:

1) Pemberian pendampingan dan pelatihan pembukuan sederhana, menjelaskan pencatatan sederhana harian, mingguan sampai bulanan. Bagaimana cara mencatat biaya - biaya produksi dan mencatat penjualan. Memisahkan keuangan pribadi dengan keuangan hasil usaha, sehingga dapat melihat keuntungan usaha secara jelas dan diharapkan nantinya dapat menyisihkan laba untuk investasi.

\section{Gambar 2. Pendampingan Pelatihan Pembukuan}

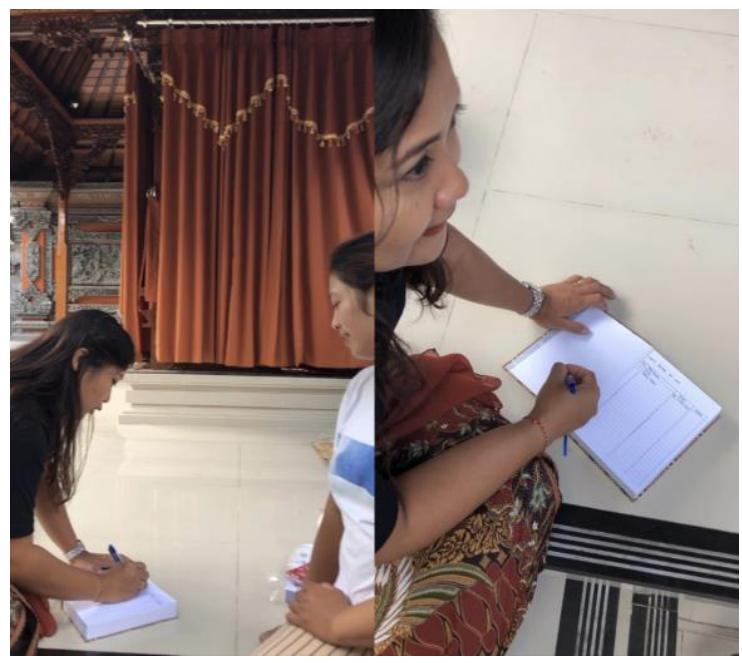

2) Pendampingan dan memberikan pelatihan akuntansi manajemen, dimana mitra dijelaskan mengenai rincian biaya produksi, harga pokok, biaya overhead yang dapat dibayarkan untuk menunjang kegiatan operasional dalam aktifitas bisnisnya. 


\section{Gambar 3. Pendampingan Pelatihan Akuntansi Manajemen}

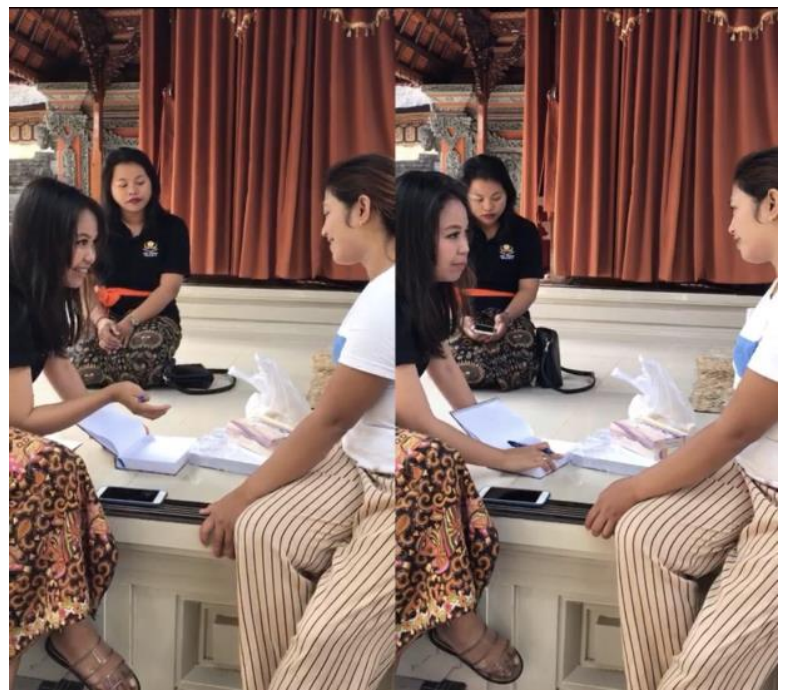

3) Pelatihan mengenai penerapan tata kelola perusahaan terutama berkaitan dengan penentuan strategi produksi maupun pemasaran, dimana membantu mitra dalam membuat kemasan baru yang lebih menarik sehingga dapat meningkatkan pemasaran serta membuat alternatif jaje sagon yang lebih bervariasi dari rasa ataupun bentuk yang lebih kekinian. Mitra diberikan gambaran mengenai contoh kemasan yang baik, dimana dalam kemasa berisikan komposisi bahan dan tanggal kadaluarsa untuk informasi kepada konsumen.

4) Membantu mitra dalam pembuatan sosial media yang dapat membantu dalam proses pemasaran produk dan memperkenalkan produk bukan hanya ke konsumen lokal Bali saja tapi kepada konsumen luar Bali sebagai alternatif oleh-oleh khas daerah Singapadu Bali.

\section{Gambar 4. Pembuatan Sosial Media dan Pelatihan Penerapan Tata Kelola} Perusahaan

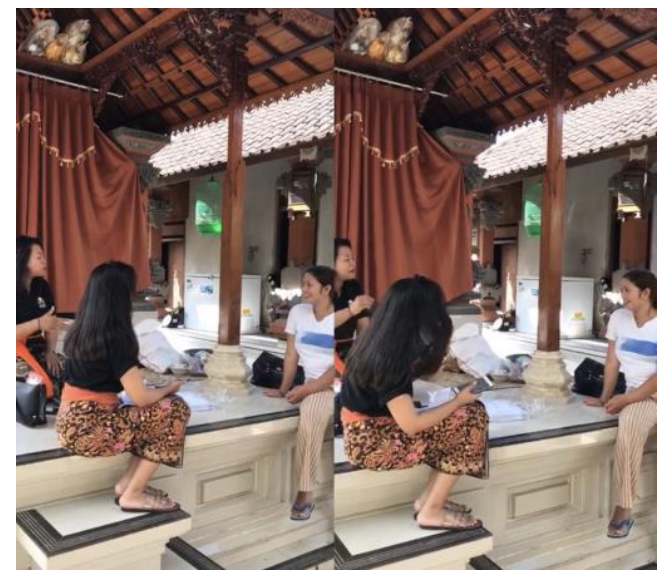

(C) 2019 Jurnal Abdi Masyarakat Universitas Kadiri | 35 
Gambar 5.4

Kunjungan ke Tempat Produksi Mitra

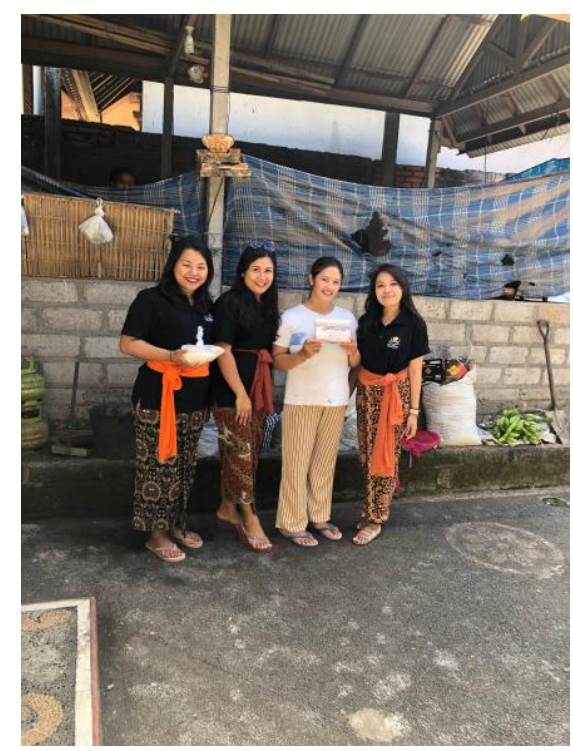

Gambar 5.5

Kemasan Baru Jaje Sagon

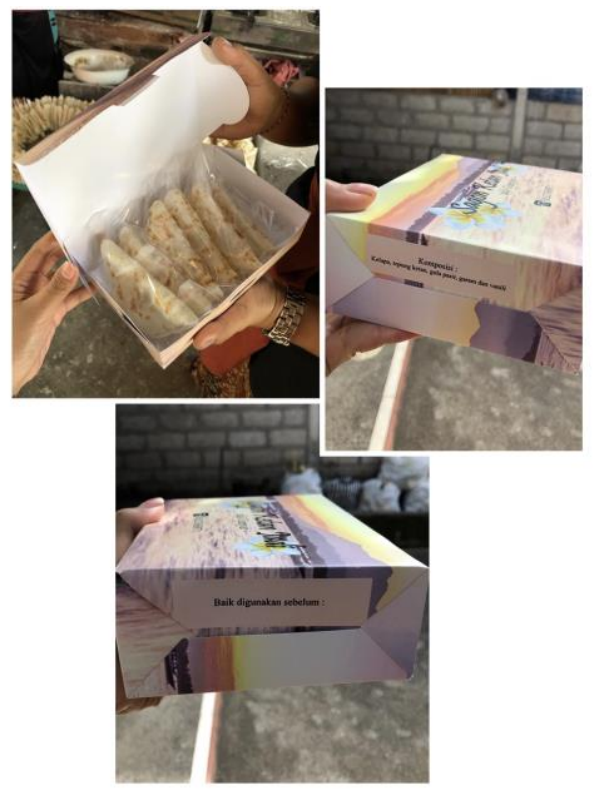

\section{DAFTAR PUSTAKA}

Bastiana Salendra Putri, Dr. Kokom Komariah. 2016. Profil Usaha Jajanan Pasar Dalam Jenis Produk, Pendapatan, Keterserapan Tenaga Kerja Di Pasar Bantengan. Jurnal Pendidikan Teknik Boga UNY - Edisi Oktober 2016

Franciscus Didik. 2013 dalam www.menuinternasional.com/2013/04/cara-membuatkue-sagon-kelapa-dan-kue.htmi 